\title{
Research on Stormwater Management of Cultural Heritage Ilmpark in Weimar Germany Based on Urban Resilience
}

\author{
Tian Lu, Yuncai Wang* \\ College of Architecture and Urban Planning (CAUP), Tongji University, Shanghai, China \\ Email: ${ }^{*}$ wyc1967@tongii.edu.cn
}

Received 20 April 2015; accepted 12 June 2015; published 15 June 2015

Copyright $@ 2015$ by authors and Scientific Research Publishing Inc.

This work is licensed under the Creative Commons Attribution International License (CC BY). http://creativecommons.org/licenses/by/4.0/

cc) (i) Open Access

\begin{abstract}
With the development of cities, problems like natural and social disasters appeared more and more frequently. For example, rapid urbanization and climate change have caused both increasing flood probability and the severity of flooding. Consequently, there is a need for all cities to develop new strategies to maintain their vitality in numerous challenges and crises. This paper in the first place reviews the concept and research fields of urban resilience; besides, according to the characteristics of the Ilmpark situated in Weimar, This paper analyzes the necessity and potential on stormwater management of this area and then it concludes the alternative strategies of improvement based on the theory of urban resilience.
\end{abstract}

Keywords

Urban Resilience, Cultural Heritage Park, Stormwater Management, Sustainable Development

\section{Introduction}

City as a complex system is becoming increasingly powerful while also becoming more and more fragile; any damage or inadaptation to new changes of subsystems can result in fatal crisis even devastate the entire city, for example, the drought and floods intrusions brought about by climate change; the destruction of the city caused by major natural disasters such as earthquakes or tsunamis; the social panic result from terrorist attacks, the spread of infectious diseases or financial crisis; the disorder of space lead by high-density development and mismanagement and so on. How the cities could actively respond to various changes and maintain its own development vitality within numerous challenges and crises have become a vital problem to be solved. The con-

*Corresponding author.

How to cite this paper: Lu, T. and Wang, Y.C. (2015) Research on Stormwater Management of Cultural Heritage Ilmpark in Weimar Germany Based on Urban Resilience. Natural Resources, 6, 398-404. http://dx.doi.org/10.4236/nr.2015.66038 
cept of urban resilience in this context has on one hand stressed the buffering capacity dealing with external shocks, and on the other hand emphasized the improvement of learning ability of the city, seizing the opportunities brought by the challenges and maintaining the development vitality.

In terms of stormwater management, usually it consists of three main areas of action: prevent the formation of flood by retaining the rainfall within the catchment area; structural flood defense by construction measures such as dams, flood walls and reservoirs; and non-structural measures, namely disaster management plans, designation of flood plains excluded from development, early warning systems, and the adaptation of housing and residential habits at ground floor level by individuals [1]. However, for heritage conservation and urban development which confronted with large-scale flood protection problems, the traditional simple engineering structural stormwater management is gradually exposed to lots of problems. A low impact development which based on Site natural hydrological cycling and conditions is needed. Learning from nature stormwater management principles and processes and studying the application of ecological stormwater management approach have practical significance to the supplement and improvement of urban stormwater management methods.

\section{Background of Urban Resilience}

\subsection{Concept and Guiding Principle of Urban Resilience}

In general, resilience refers to the ability of human settlements to withstand and to recover quickly from any plausible hazards. Resilience Alliance claimed that urban resilience mainly related to the following three characteristics in the social-ecological system: 1) the amount of change the system can undergo and still retain the same controls on function and structure; 2) the degree to which the system is capable of self-organization; and 3) the ability to build and increase the capacity for learning and adaptation. So it is not only refers to reducing risks and damage from disasters but also the ability to quickly bounce back to a stable state.

UN-Habitat's City Resilience Profiling Program introduced the following ten guiding principles and features about how can cities become more resilient: 1) put place in organization and coordination to understand and reduce disaster risk, based on the participation of citizen groups and civil society. Build local alliances. Ensure that all departments understand their role in disaster risk reduction and preparedness; 2) assign a budget for disaster risk reduction and provide incentives for homeowners, low-income families, communities, businesses, and public sector to invest in reducing the risks they face; 3) maintain up-to-date data on hazards and vulnerabilities, prepare risk assessments, and use these as the basis for urban development plans and decisions. Ensure that this information and the plans for your city's resilience are readily available to the public and fully discussed with them; 4) invest in and maintain critical infrastructure that reduces risk, such as flood drainage, adjusted where needed to cope with climate change; 5) assess the safety of all schools and health facilities and upgrade these as necessary; 6) apply and enforce realistic risk compliant building regulations and land use planning principles. Identify safe land for low-income citizens and upgrade informal settlements, wherever feasible; 7) ensure education programs and training on disaster risk reduction are in place in schools and local communities; 8) protect ecosystems and natural buffers to mitigate floods, storm surges, and other hazards to which your city may be vulnerable. Adapt to climate change by building on good risk reduction practices; 9) install early warning systems and emergency management capacities in your city, and hold regular public preparedness drills; 10) after any disaster, ensure that the needs of the survivors are placed at the center of reconstruction, while supporting them and their community organizations to design and help implement responses, including rebuilding homes and livelihoods [2].

\subsection{Research Field of Urban Resilience}

From the beginning of 1990s, the theory of urban resilience has been taken into urban development practice, with the development of this theory, current academia mainly research on the following four aspects: ecological resilience, engineering resilience, economic resilience and social resiliency. Each of them has different points of focus which support the improvement of urban resilience theory together.

1) Ecological resilience

Urban ecological resilience refers to the extent of adapting the change before re-organization and forming the new structures and processes of urban ecosystem [3]. The political, economic and social activities both influence the ecological processes of the city and depend on the support of ecosystems, therefore the research focus of ur- 
ban ecological resilience is to build an organizational system which can react to the services of ecosystem.

2) Economic resilience

Urban economic resilience is flexibly coping strategy to avoid potential losses after external attack to individuals and communities occur; it is an innate responding ability and adaptation to natural or social disasters of a system [4]. It concerns that the impact of attacks to urban economic activities and people's lives, at the same time it assesses the property damage caused by disaster.

3) Social resilience

Adger is the first scholar who extended the concept of economic resilience to the field of human society; he considered that social resilience includes the capabilities of respond to the outside pressure brought by social, political and environmental changes of community groups [5]. It concerns the establishment of social stability and social order, and mainly research on the impact of external events on the overall society.

4) Engineering resilience

Engineering resilience mainly emphasize the ability of urban infrastructure systems, residents and communities to efficiently recover from natural and man-made disasters [6]. It requires the cities to adopt the disaster mitigation technology, strengthen infrastructure to increase urban infrastructure resilience, in order to ensure the economic activity function properly.

\subsection{The Relationship between Urban Cultural Heritage Park and Urban Resilience}

Urban cultural heritage park could make a city more resilient mainly in two aspects: ecological resilience and social resilience.

1) Ecological resilience

Urban Park is an open space or area. The common feature of the entire urban park is that they are constituted by greenland with the function of ecology, beautification and hazard prevention and reduction. As the city's main source of green plants, urban parks not only can effectively improve the ecological environment of the city as an urban oasis in the city also has ecological function of regulating climate, wind, sand, dust and noise reduction, conservation of the groundwater, it is also reflected urban civilization, cultural and history of the city as an important landscape carrier and a concentrated expression of cityscape. Construction of urban parks, aims to coordinate the relationship between urban development and environmental protection, therefore, on the road of sustainable development, the urban park plays an invaluable role in urban resilience.

2) Social resilience

Urban cultural heritage parks full of social-ecological memories carry experiences which are critical parts of any social-ecological system, providing sources of resilience to deal with various disturbances to metropolitan landscapes and the society. The memories in this respect should rather be understood as relations among individuals and communities that contain experiences and knowledge in specific places. They carry not only physical features of the urban environment that perform resilient memory work but also the people and their interaction in urban-nature practices that manage those features. Urban cultural heritage parks also serve as reminders of alternative uses of urban space and as opportunities to protect and foster eco-systems and public health services. If urban green spaces are transformed into brown or grey spaces such social-ecological memories may disappear from the urban mind [7].

\section{The Stormwater Management in Ilmpark of Weimar}

\subsection{Background of Ilmpark}

The Ilmpark is situated in Weimar-an historical urban district and with 65,000 inhabitants in Thuringia of Germany as Figure 1 shows. The park is located on both banks of the Ilmriver for 1.0 kilometer from the castle in the north to the suburb of Oberweimar in the south. The park forms part of the floodplain of the Ilmriver. It is about $1.5 \mathrm{~km}$ long and covers about $0.48 \mathrm{~km}^{2}$. The soil of the floodplain is alluvial clay; the park is part of a much longer greenway along the river, including the park of Belvedere in the north and the park of Tiefurt.

Climatically Weimar belongs to the dry environment of the Thuringian basin leeward of Thuringia Mountains with beech forests. The annual precipitation is about $557 \mathrm{~mm}$; the prevailing wind directions are southwest, west and northwest. The average annual temperature is $8.3^{\circ} \mathrm{C}$, with an average of $-0.7^{\circ} \mathrm{C}$ in January and $17.2^{\circ} \mathrm{C}$ in July [8]. 




(a)

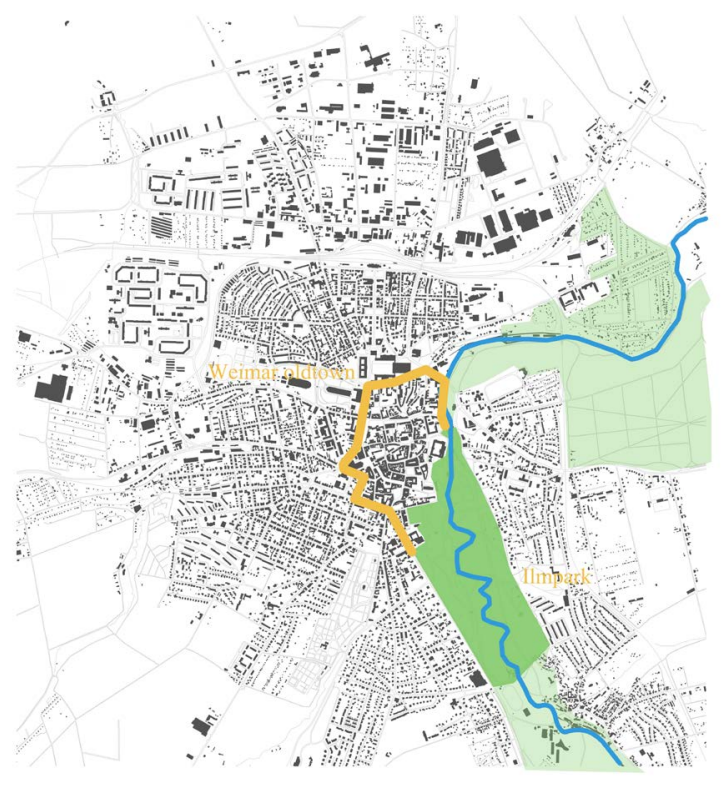

(b)

Figure 1. Location analysis of Greenway in Weimar (a) and (b). Source: Stiftung Weimarer Klassik.

The origin of the Ilmpark dates back to 1778. It was based on formal gardens, near the ducal city palace, dating back 100 years, situated on what at the time was the outskirt of Weimar. Some artistic improvisations were made in the Ilm valley. From those improvisations the park developed in three stages. The first stage from 1778 to 1786 was heavily influenced by the Age of Sensibility. With the involvement of J. W. Goethe some small memorial sites were placed in the historic cultural landscape of the Ilm valley, e.g. the "Schlangenstein" and the "Dessaustein". The second stage from 1786 to 1798 during the period of Weimar Classicism saw larger park spaces emerge from the small memorial sites, using the existing relief and parts of the former cultural landscape like meadows and small groves. The "Roman House" and the vistas that were created with its construction are typical of this period .During the third stage after 1798, the post-classic period, the landscape garden reached its present extent. This period was influenced by Duke Carl August's growing interest in botany and horticulture, resulting in the increased introduction of non-native plant species. These species were often planted near the "Roman House", the summer residence of Carl August. From then there were no great changes to the base structure of the park until the middle of the twentieth century. In 1860 the city of Weimar began to enclose the park, starting with the construction of mansions on the "Belvedere Avenue" west of the park and the so called "Horn" in the east. During this time the river Ilm flooded the floodplains periodically, but with increasing river training in the twentieth century flooding has nearly disappeared.

During the last months of World War II the Ilmpark was damaged by air raids. After the end of the war a small part of the park was used as a Soviet memorial cemetery as remains so today. A partly marginal management, increased recreational use and insensitive development further damaged the park during the second half of the twentieth century. For example hay meadows on the floodplain cut twice-yearly have become short-mown, cut twenty times a year. Nevertheless the Ilmpark was included as part of the "Classic Weimar" UNESCOWorld Heritage Site in 1998 [9] (Figure 2 for a general overview).

\subsection{Current Situation of Stormwater Management in Ilmpark}

1.43 trillion liters of water fall down between $30^{\text {th }}$ May and $2^{\text {nd }}$ June in 2013 in Thuringia as Figure 3 shows. The floods in late May and early June 2013 caused extensive flooding and significant property damage in the amount of 450 million euros [10].

According to the statistics, the flood disaster appeared increasingly frequent in recent years. Even though from the statistics we could figure out that among the areas along the Ilm river the place where Ilmpark located suffer lighter than the rest, the park truly to some extent eased the aftermath of flooding: considering the existing terrain advantages of the English landscape park, The stormwater management here primarily through its the 

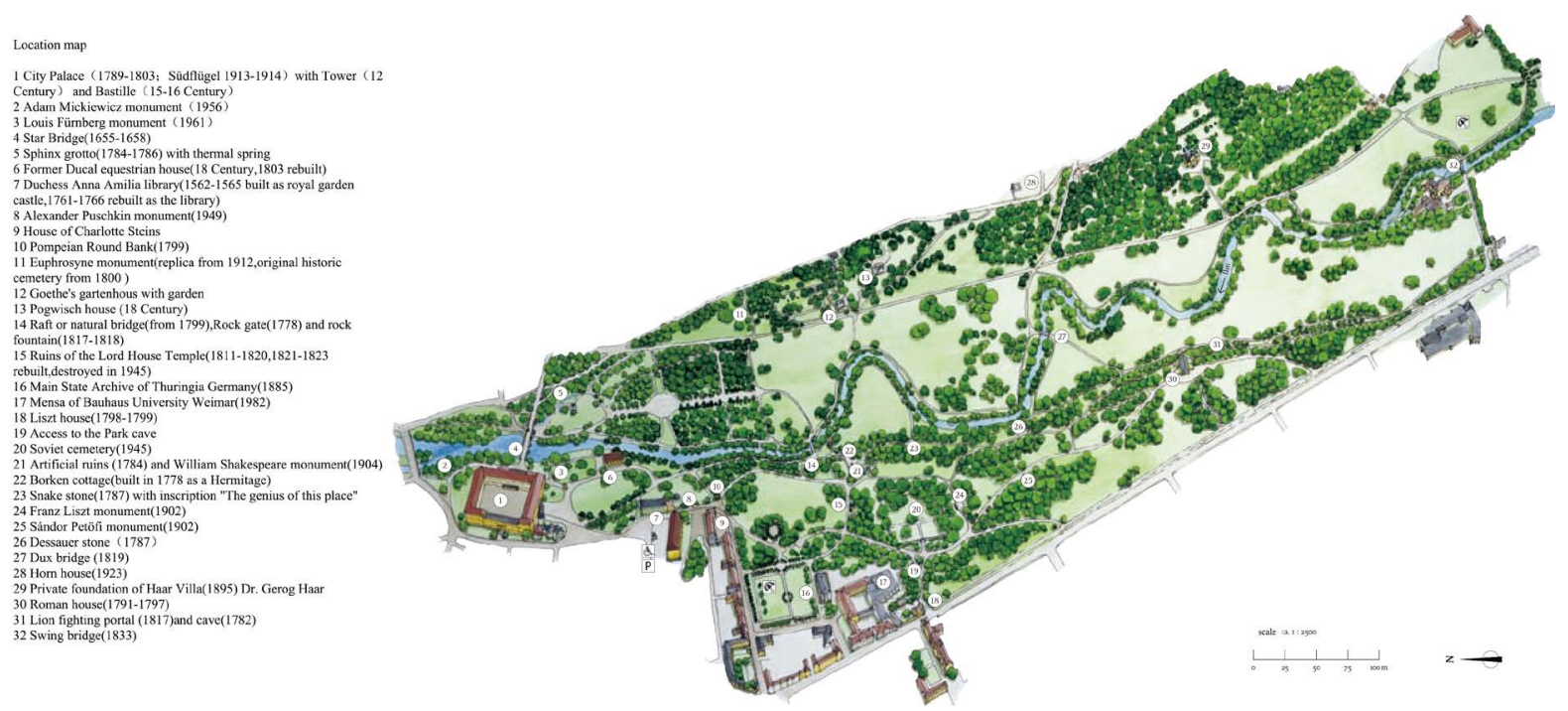

Figure 2. Current master plan of Ilmpark. Source: Stiftung Weimarer Klassik.

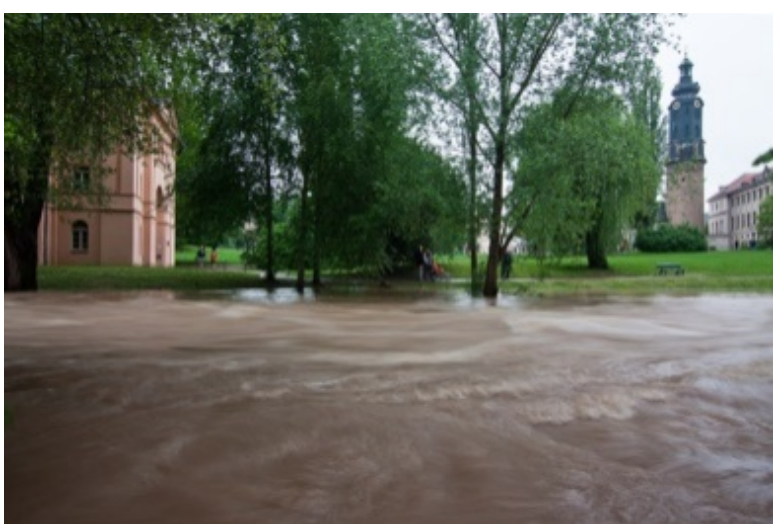

(a)

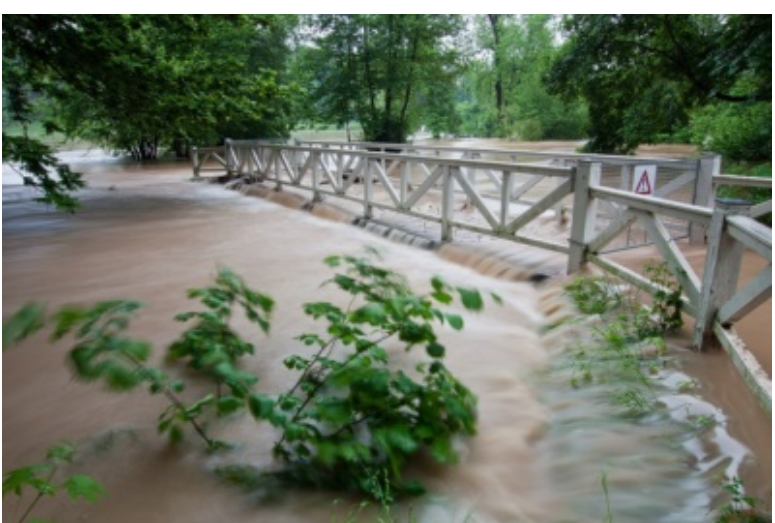

(b)

Figure 3. The situation of floods of Ilmpark in 2013 (a) and (b). Source: Markus Weggässer, Hochwasser Mai/Juni 2013, Thüringer Landesanstaltfür Umwelt und Geologie, 2013.

collection of rainwater by the low-lying greenland which used as an alternative to the role of drainage channels, These rainwater collected by means of Greenland has less pollution, is more appropriate for vegetation to be watered and transpiration, saving costs and at the same time having great ecological significance. Meanwhile, the design of the park combined lawn and micro terrain comprehensively, creating distinct levels of landscape effects. And it through directing the flow of rainwater has achieved a dual purpose of reducing surface runoff and watering vegetation.

Nevertheless, there are still some unoptimistic facts attract less attention: Firstly, the accelerated urbanization process have produced more pollutants to contaminate the water in the Ilm river; Secondly, Weimar has a characteristics of huge rainfall, it needs flood protection at the same time the rainfall has high value of reuse; Thirdly, the park has rich terrain and geomorphic types, how to more effectively take advantage of terrain features to form landscape and achieve sustainable development of the city need the support of more developed sustainable stormwater management techniques.

\subsection{The Potentials and Strategies of Stormwater Management in Ilmpark}

Through numerous observation and research of the author (Figure 4), the main potentials of stormwater management in Ilmpark are as follows: Firstly, the utilization rate of rainwater is low. Secondly, the network of water system is destroyed. Thirdly, the vegetation level on the revetment is too simple. 


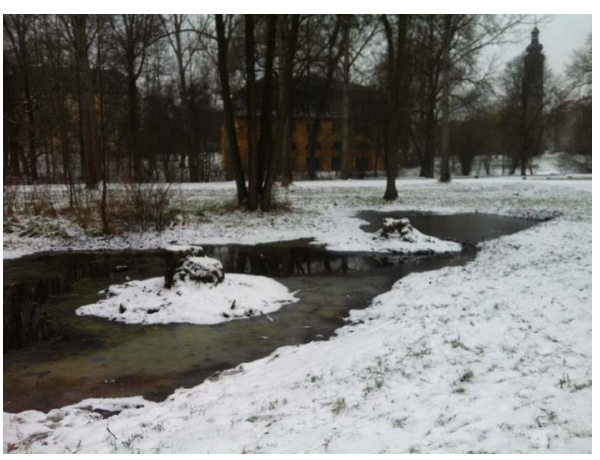

(a)

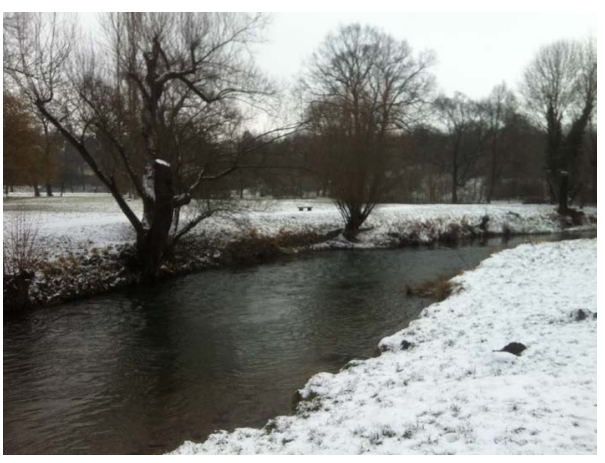

(b)

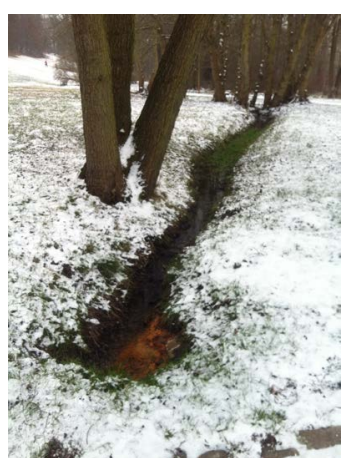

(c)

Figure 4. Current situation of stormwater management in Ilmpark (a)-(c). Source: author's investigation.

Based on the current situation, several strategies could be put into use:

1) On the premise of meeting the proper function, urban park landscape design could combine with stormwater management. Rainwater planting ditch, rainwater filter strips, rainwater planting pools, permeable pavement and other stormwater landscape facilities can be designed in the park fringe area, focusing on the surrounding buildings, roads and stormwater management in the marginal area.

2) Focusing on the connection of water system, integration of canals and ponds, in order to achieve unity of regulation and storage of rainwater and effective usage. In addition to the connectivity of water system distribution inside the park, the outside edge of the park area and park internal stormwater management facilities can communicate with each other, in order to achieve the largest stormwater management abilities of the park. If conditions permit, park stormwater management and other urban public green stormwater management facilities should form a system, obtaining the largest urban green stormwater management efficiency.

3) Create Riparian Buffer. Riparian Buffer is ecological landscape with stormwater management which mainly build with different plant communities, namely waterfront trees, shrubs, herbaceous, and permeable material such as waterfront soil and gravel. The first layer is mainly composed by perennial grasses, along with other herbs and woody plants, reducing runoff velocity and absorbing pollutants in stormwater treatment. The second layer is mainly composed of slow-growing trees and shrubs; further purifying and managing the remaining contaminants from the first layer plant while providing good habitat for wildlife. The third layer is mainly composed of fast-growing and waterproof trees, reeds and wetlands. According to different terrain and the depth of water reasonably design emerged plants, submerged plants, floating plants in the wetland, complete the last administration of Stormwater quantity and quality, while protecting the banks and create a more stable habitat for aquatic organisms.

As a consequence, the roots of plant could anchor the soil, the foliage of plant could keep rainwater to filter surface runoff, resist water erosion, protect the embankment, reserve a large amount of rain water and not only alleviate flooding, but also supply underground water, increase bank stability and the microbe in wetland can degrade toxic substances; retain the impurities and sediment, as a result strengthen the role of water purification and water conservation, at the same time, naturally form the ecological landscape.

\section{Conclusion}

Cities in the development process always faced with intrusions natural disaster or various social issues; related actions should be taken under the guidance of the concept of urban resilience in order to mitigate those impacts, damages and risks. When facing the situation of combination of natural and cultural heritage such as Ilmpark, natural, biological, cultural, urban expansion process and many interests of ecological, social and economic are intertwined. The flood problems would never be solved with the original monolithic construction, and seeking for a comprehensive settlement through the entire landscape process of the heritage area is needed. Through establishing the ecological infrastructure, identifying the key point of controlling these processes, building up appropriate landscape security pattern, multiple relationships are coordinated and the security of ecology and heritage in the regional can be protected, as a result, the city can be more resilient. Obviously, the development of urban resilience is closely involved with different departments of government, communities, educational institu- 
tions, social security institutions, planning and design companies and many other sectors, only achieving the whole process of urban resilience construction from the technique to policy can truly implement the theory and benefit for urban development and people's lives.

\section{Acknowledgements}

This paper is supported by the project of "The Pattern language and its mechanism of traditional culture landscape space” in the National Natural Science Foundation of Chinese (No. 51278346). We are grateful to Dipl.Ing. Nicole Baron of Bauhaus University Weimar for valuable guidance and support.

\section{References}

[1] Lieske, H. (2012) Flood Hazards, Urban Waterfronts, and Cultural Heritage. In: Kabisch, S.K., Kunath, A.K., Schweizer Ries, P. and Steinführer, A., Eds, Vulnerability, Risk and Complexity: Impacts of Global Change on Human Habitats, Hogrefe, Göttingen; Advances in People-Environment Studies, 3, 89-100.

[2] UN-Habitat. Resilience (2014) http://unhabitat.org/urban-knowledge/urban-lectures/

[3] Holling, C.S. (1996) Engineering Resilience versus Ecological Resilience. National Academy Press, Washington DC, 31-44.

[4] Rose, A. (2004) Defining and Measuring Economic Resilience to Disasters. Disaster Prevention and Management, 13, 307-314. http://dx.doi.org/10.1108/09653560410556528

[5] Ader, N.W. (2000) Social and Ecological Resilience: Are They Related? Progress in Human Geography, 24, $347-364$. http://dx.doi.org/10.1191/030913200701540465

[6] Jianming, C., Hua, G. and Degen, W. (2012) Literature Review on Urban Resilience. Progress in Geography, 31, 1245-1255.

[7] Stephan, B., Sverker, S. and John, L. (2010) Innovative Memory and Resilient Cities-Echoes from Ancient Constantinople, In: Paul, J.J., Sinclair, G.N., Frands, H. and Christian, I., Eds., The Urban Mind: Cultural and Environmental Dynamics, Department of Archaeology and Ancient History, Uppsala University, Uppsala, 391-405.

[8] Salzmann, M. (1999) Naturraum, Oberflähenform und Klima. In: Grundmann, L., Ed., Weimar und seine Umgebung, Bölhaus Nachfolger, Weimar, 2-5.

[9] Martin, K. and Norbert, M. (2008) Ilmpark-Weimar (UNESCO World Heritage Site)—Historical Landscape Gardens in Central Europe as Early Heritages for the Development of Ecological Designed Parks. "Urban Biodiversity and Design” Implementing the Convention on Biological Diversity in Towns and Cities. Third Conference of the Competence Network Urban Ecology, Bundesamtfür Naturschutz (BfN), 27-44.

[10] Markus, W. (2013) Hochwasser Mai/Juni 2013. http://storm-chasing.de/extrem/hochwasser/114-mai-juni-hochwasser-2013 